\title{
METAL-CHELATE-DENDRIMER-ANTIBODY CONSTRUCTS FOR USE IN RADIOIMMUNOTHERAPY AND IMAGING
}

\author{
Chuanchu Wu*, Martin W. Brechbiel, Robert W. Kozak+ and Otto A. Gansow* \\ Chemistry Section, Radiation Oncology Branch, National Instituses of Health, \\ and ${ }^{+}$Center for Biologics Evaluation, Food and Drug Administration, Bethesda, MD 20892, USA,
}

\begin{abstract}
Polyamidoamine dendrimers were modified chemically by reaction with DOTA and DTPA type bifunctional metal chelators and were coupled to monoclonal antibody 2E4 without loss of protein immunoreactivity. Both the DTPA- and DOTA-dendrimer-antibody constructs were easily labeled with ${ }^{90} \mathrm{Y},{ }^{111} \mathrm{In},{ }^{212} \mathrm{Bi}$ or cold Gd(III) suggesting use of this dendrimer-macrocycle for mAb guided radiotherapy or imaging.
\end{abstract}

Monoclonal antibodies (mAb) are proving useful for tumor-targeted delivery of radioactivity for use in diagnostic imaging and radiotherapy. 1,2 Bifunctional chelating agents which possess both a reactive functional group for protein linkage and a metal binding site are often used for radiolabeling. ${ }^{3-6}$ Despite their extraordinary stability in vivo and in vitro, use of macrocyclic chelating ligands such as DOTA ${ }^{7-11}$ for labeling $\mathrm{mAb}$ with cytocidal radiometals ${ }^{12-16}$ such as ${ }^{90} \mathrm{Y}$ and ${ }^{212} \mathrm{Bi}$ for use in radioimmunotherapy has been impeded by the slow reaction kinetics of formation of the corresponding metal-DOTA complexes. ${ }^{11,16,17}$ Attempts to improve kinetics by introduction of more than a few chelating groups into the immunoprotein structure usually result in substantial loss of mAb immunoreactivity. ${ }^{18}$ To obviate these problems, we now report the preparation of dendrimer-based DOTA chelators and methods for their linkage to $\mathrm{mAb}$. The antibody-dendrimer-DOTA constructs thus produced radiolabel with ${ }^{9} \mathrm{Y}$ efficiently to produce quite high specific activity radioimmunoconjugates.

The prospect of using dendrimers for chemical modification of antibodies has received little attention in the literature. Lavallee and co-workers reported ${ }^{19}$ use of a dendrimer as a linker between a porphyrin and oxidized carbohydrate of polyclonal rabbit IgG; and, in two meeting abstracts from Barth's group, ${ }^{20,21}$ the product of coupling polyhedral-borane-coated dendrimers to the B16 melanoma mAb is described. While other polymers have been used similarly as carriers for chelators, ${ }^{22-26}$ the Starburst ${ }^{\mathrm{TM}}$ dendrimers ${ }^{27}$ offered inherent symmetry, uniform surface chemistry, minimal molecular weight distribution and shape variation which allowed us to reproducibly synthesize homogeneous constructs which were easily separable from unmodified mAb.

Herein we report the successful coupling with minimal loss of immunoreactivity of a single mAb molecule to a polyamidoamine (PAMAM) dendrimer (Generation 2, i.e., $G=2$ ) with 10.2 of the available 12 surface primary amines coated with the DOTA chelator. For comparison, the $G=2$ dendrimer with 10.6 DTPA ligands linked per dendrimer was coupled to $\mathrm{mAb}$ and used in devising radiolabeling protocols.

Preparation of antibody-dendrimer-chelates conjugates was achieved as outlined in Scheme 1. The dendrimer $\left(\mathrm{G}=2,10 \mu \mathrm{M}\right.$ in $\left.8 \mathrm{~mL} \mathrm{H}_{2} \mathrm{O}\right)$ was reacted with the ${ }^{14} \mathrm{C}$-labeled bifunctional ligands $\mathrm{N}$-[2-amino-3-(pisothiocyanatophenyl)propyl]-trans-cyclohexane-1,2-diamine- $N, N^{\prime}, N^{\prime}, N^{\prime \prime}, N^{\prime \prime}$-pentaacetic acid $[(A), p-S C N$. Bz-CHX-B-DTPA, $168 \mu \mathrm{M}]^{28}$ or 2-(p-isothiocyanatobenzyl)-1,4,7,10-tetra-azacyclododecane-N, $N^{\prime}, N^{\prime \prime}$, $\mathrm{N}^{\prime \prime}$ - tetraacetic acid $[(\mathrm{B}), \mathrm{p}-\mathrm{SCN}-\mathrm{Bz}-\mathrm{DOTA}, 150 \mu \mathrm{M}]^{29}$ at $40^{\circ} \mathrm{C}, \mathrm{pH} 9$, for 24 hours. One half of

Abbreviations: DOTA $=1,4,7,10$-tetraazacyclododecanetetraacetic acid; DTPA $=$ diethylenetriaminepentaacetic acid; $P B S=$ Phosphate buffered saline. 


\section{Scheme 1}
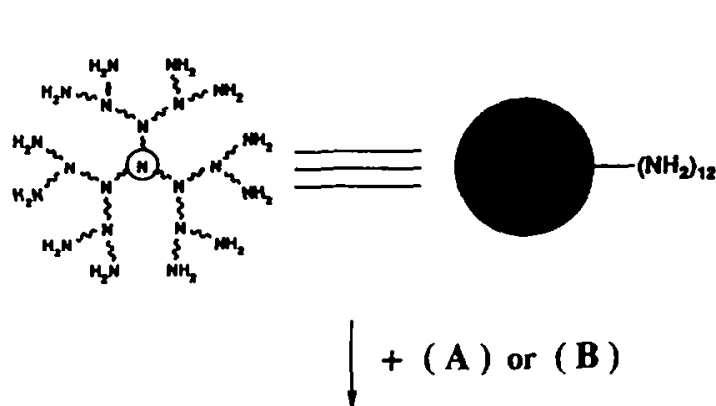

2

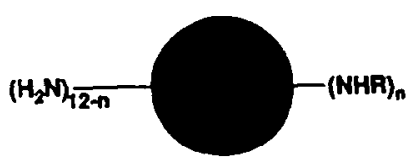

\section{Sulfo-LC-SPDP} pH 8.0

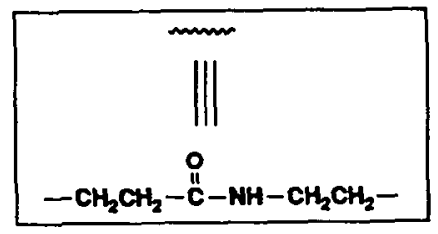

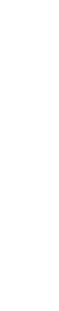

3

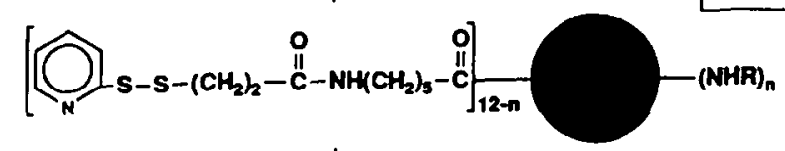

DTT, pH 8.0

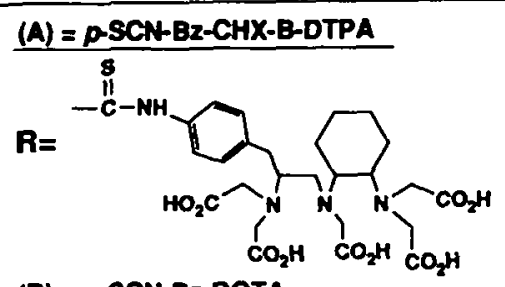

(B) = p-SCKk-B2-DOTA

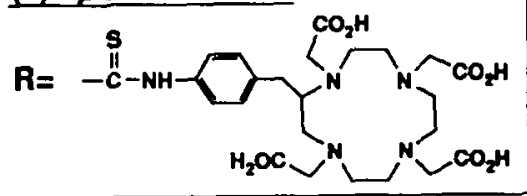

4

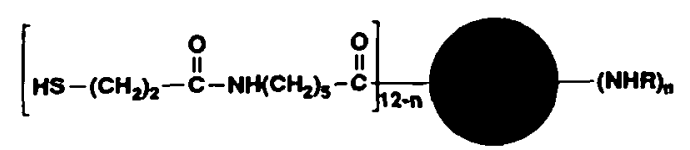

pH 7.0; Rm. Temp. $30-60 \mathrm{~min}$.
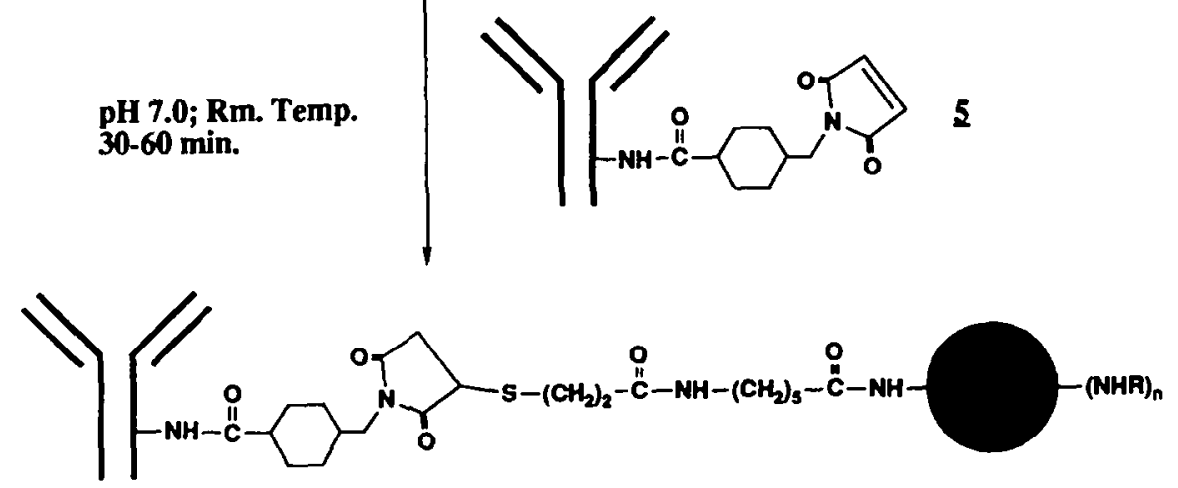
the isothiocyanate was added as a solid and the solution adjusted to $\mathrm{pH} 9.0$ with $0.2 \mathrm{M} \mathrm{NaOH}$ to initiate the reaction. The remainder was added after 8 hours and the $\mathrm{pH}$ of the reaction mixture again adjusted to $\mathrm{pH} 9.0$. Unreacted ligand was removed by ultrafiltration with $0.1 \mathrm{M} \mathrm{NaCl}$ by using a stirred cell (Amicon, MA) fitted with an Omega 3K membrane (Filtron, MA). Progress of the ultrafiltration was conveniently monitored by ligand uv absorption $\left[\lambda=280, \varepsilon=7,500 \mathrm{~cm}^{-1} \mathrm{M}^{-1}\right.$ for $(A)$ and $7,350 \mathrm{~cm}^{-1} \mathrm{M}^{-1}$ for $\left.(B)\right]$ and size exclusion HPLC on a TSK$2000 S W_{x l}$ column $(7.8 \times 300 \mathrm{~mm}$ ) eluted with PBS, pH7.2 at the flow rate of $0.8 \mathrm{~mL} / \mathrm{min}$. The resulting solute was lyophilized to obtain dendrimer-ligand conjugates 2 at yields of $73 \%(\mathrm{~A})$ and $54 \%(\mathrm{~B})$. The average number of ligands linked to dendrimer was determined by integration of ligand aromatic proton NMR resonances versus alkyl signals and was found to be 10.6(A) and 10.2(B) for the DTPA and DOTA, respectively.

To provide a free thiol source, the remaining primary amines on 2 ( $5 \mathrm{mM}$ in $5 \mathrm{~mL}$ of $0.1 \mathrm{M}$ HEPES buffer, $\mathrm{pH}$ 8.0) were reacted with a 5 fold molar excess of sulfosuccinimidyl 6-[3'-(2-pyridyldithio)-propionamido] hexanoate, (sulfo-LC-SPDP, Pierce Chemical Co.) for 1 hour at room temperature. Solid dithiothreitol (DTT) was added to $25 \mathrm{mM}$ concentration and reacted with 3 for $15 \mathrm{~min}$ to generate sulfhydryls. ${ }^{30}$ The sulfhydrylcontaining dendrimer conjugate 4 was separated from low molecular weight impurities by ultrafiltration as described above and lyophilized. Ellman's reagent ${ }^{31}$ was used to quantitate sulfhydryl groups. The average number of sulfhydryls was found to be $1.8 \pm 0.4(\mathrm{~A})$ and $2.0 \pm 0.3(\mathrm{~B})$ indicating that all primary amino groups of 2 had been saturated with sulfo-LC-SPDP. Further, solutions of 4 tested negative for amine when reacted with fluorescamine. ${ }^{32}$

Conveniently, the product 3 may be isolated for storage by ultrafiltration and lyophilization. The extent of 2-pyridyl disulphide modification is determinable by the increase in uv absorbance at $343 \mathrm{~nm}$ after reduction with $\mathrm{DTT}^{30}$ and was found for 3 to be $1.6 \pm 0.3(\mathrm{~A})$ and $2.1 \pm 0.5(\mathrm{~B})$, in good agreement with the sulfhydryl quantitation by Ellman's method. Prior to use with immunoprotein, 3 may be converted by DTT reduction to 4 and purified on a column $(2 \times 20 \mathrm{~mm})$ of MP-1 anion exchange resin. ${ }^{33}$

Dendrimer ligand construct 4 was then conjugated to $\mathrm{mAb}$ which had been previously modified by the heterobifunctional coupling reagent sulfo-SMCC (sulfosuccinimidyl 4-(N-maleimidomethyl) cyclohexane-1carboxylate, Pierce Chemical $\mathrm{Co}$.) according to well defined methods. ${ }^{34}$ Antibody-dendrimer-ligand conjugates were separated from unmodified antibody, unreacted polychelate 4 , and higher molecular weight species arising from multiple sulfhydryl groups attached to dendrimer by HPLC using a MONO $Q$ anion exchange column ( $5 \times$ $50 \mathrm{~mm}$, Pharmacia, Sweden) coupled in tandem with a TSK 3000 SW preparative size exclusion column $(21 \times$ $600 \mathrm{~mm}$, TosoHaas, Japan) by a Pharmacia V7 valve.35 The final molar ratio of 4 to mAb was obtained by separately measuring protein concentration by using BCA reagent (Pierce, IL) and by determining ligand concentration by ${ }^{14} \mathrm{C}$ liquid scintillation counting. In the final product, the measured ratios of dendrimer-ligand conjugate to protein were always unity $(1.00 \pm 0.05)$.

To demonstrate retention of immunoreactivity of such a modified $m A b$, Den-CHX-B-DTPA conjugated to mAb 2E4 was labeled with ${ }^{111}{ }^{1},{ }^{3}$ and incubated with its target cells (5.1.2) under conditions of antigen excess (10 ng labeled antibody/10 million cells) or an equivalent amount of non-target cells (RAJI) as control. The high bindings of the modified mAb to its target cells, $76.6 \%$, clearly indicated that the modification of $\mathrm{mAb}$ with dendrimer conjugated ligands has no significant effect on their immunoreactivities. ${ }^{36}$

In order to evaluate the effect of the dendrimer-DOTA-antibody construct on the rate of $Y$ (III) complex formation, we examined the labeling of bovine IgG-Den-DOTA compared with IgG-DOTA (1.20 ligand/IgG) with ${ }^{90}$ Y. As shown in Fig.1, the time necessary to reach complete complexation (>95\%) with IgG-Den-DOTA 
conjugates was about 3 hours at room temperature $\left(20^{\circ} \mathrm{C}\right)$ and $30 \mathrm{~min}$ at $35^{\circ} \mathrm{C}$, while IgG-DOTA chelated $<5 \%$ of available ${ }^{90} \mathrm{Y}$ at room temperature and $15 \%$ at $35^{\circ} \mathrm{C}$ over the same time period. Note that the experiments for this comparison were designed to give same initial ${ }^{90} \mathrm{Y}$ to ligand ratios, i.e. the same $\mu \mathrm{Ci} / \mu \mathrm{M}$ in the reactions.

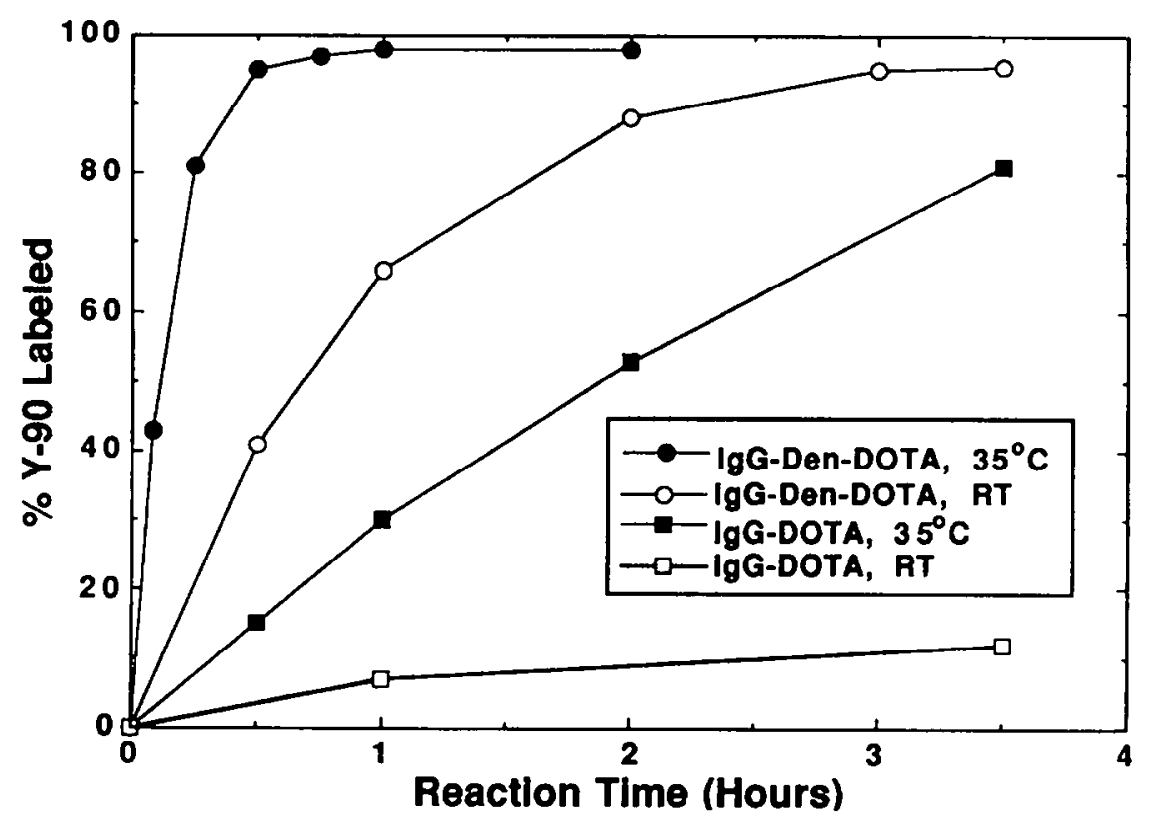

Figure 1: Radiolabeling of IgG conjugates with ${ }^{90} \mathrm{Y} .50 \mu \mathrm{g}$ of bovine IgG-Den-DOTA or $412 \mu \mathrm{g}$ of IgG-DOTA were labeled in $0.1 \mathrm{M} \mathrm{NH} \mathrm{NAAc}_{4} \mathrm{pH} 5.6$ with $500 \mu \mathrm{Ci}$ of ${ }^{90} \mathrm{Y}$ at $\mathrm{RT}$ or $35^{\circ} \mathrm{C}$. The molar ratios of DOTA to protein were 9.88 for IgG-Den-DOTA and 1.20 for IgG-DOTA. Therefore, the initial ratios of ${ }^{90} \mathrm{Y}$ to DOTA, i.e., $\mu \mathrm{Ci} / \mu \mathrm{M}$, were equivalent in all of the reactions.

The highest specific activities obtained for ${ }^{90} \mathrm{Y}$-labeled IgG-Den-DOTA were $47 \mathrm{mCi} / \mathrm{mg}$ at $35^{\circ} \mathrm{C}$ and 15 $\mathrm{mCi} / \mathrm{mg}$ at room temperature with only $30 \mathrm{~min}$. incubation. In contrast, under similar conditions ${ }^{90} \mathrm{Y}$ labeling of mAbs directly conjugated with DOTA at 1:1 DOTA to protein molar ratio failed to produce a product with even 1 $\mathrm{mCi} / \mathrm{mg}$ specific activity. Radioyttrium labeling did not alter $\mathrm{mAb}$ immunoreactivity. Similarly, labeling $\mathrm{mAb}$ Den-CHX-B-DTPA with ${ }^{212} \mathrm{Bi}$ resulted in greater than $60 \mathrm{mCi} / \mathrm{mg}$ specific activity, while the highest specific activity we had previously obtained with one CHX-B-DTPA directly conjugated to one mAb molecule was 15 $\mathrm{mCi} / \mathrm{mg}$. Cold $\mathrm{Gd}(\mathrm{III})$ complexes also readily formed with DOTA- and DTPA-dendrimer-mAb conjugates.

Our results demonstrate that we have developed a new and potentially useful class of protein modification reagents. The methodology presented here provides a simple route to modifying mAbs with a high number of chelating agents and without major loss of mAb immunoreactivity than was possible by using conventional direct ligand attachment techniques. Employment of the mAb-Den-DOTA construct obviated the slow Y(III)-DOTA complex formation kinetics, encouraging exploitation of the exquisite stability of ${ }^{90}$ Y-DOTA for radioimmunotherapy. Use of similar dendrimer constructs ${ }^{37}$ for introducing large numbers of Gd(III) chelates into biologically important molecules for targeted MRI imaging is under investigation.

Acknowledgment: We would like to thank Dr. Guiying Li, NIH, for performing NMR measurements. 


\section{REFERENCES AND NOTES}

1. Liu, Y.; Wu, C. Pure Appl. Chem. 1991, 3, 427-463.

2. Scheinberg, D., Strand, M, and Gansow, O.A. Science, 215, 1511-1514, 1982.

3. Mirzadeh, S.; Brechbiel, M.W.; Atcher, R.W.; Gansow, O.A. Bioconjugate Chem. 1990, 1, 59-65.

4. Hnatowich, D.J.; Childs, R.L.; Lanteigne, D.; Najafi, A. J. Immunol. Methods 1983, 65, 147-157.

5. Paik, C.H.; Hong, J.J.; Ebbert, M.A.; Heald, S.C.; Reba, R.C.; Eckelman, W.C. J. Nucl. Med. 1985, 26,482-487.

6. Meares, C.F.; McCall, M.J.; Reardan, D.T.; Goodwin, D.A.; Anal. Biochem. 1984, 142, 68-78.

7. Wu, C.; Brechbiel, M.W.; McMurry, T.J.; Pippin, C.G.; Gansow, O.A. J. Nucl. Med. 1992, Suppl. 1031.

8. Camera, L.; Kinuya, S.; Garmestani, K.; Wu, C.; Brechbiel M.W.; Pai, L.H.; McMurry, T.J.; Gansow, O.A.; Pastan, I.; Paik, C.H.; Carrasquillo J.A. Submitted to J. Nucl. Med.

9. Moi, M.K.; Meares, C.F. J. Am. Chem. Soc. 1988, 110, 6266-6267.

10. Deshpande, S.V.; DeNardo, S.J.; Kukis, D.L.; Moi, M.K.; McCall, M.J.; DeNardo, G.L.; Meares, C.F. J. Nucl. Med. $1990,31,473-479$.

11. Broan, C.J.; Cox, J.P.L.; Craig, A.S.; Kataky, R.; Parker, D.; Harrison, A.; Randall, A.M.; Ferguson, G. J. Chem. Soc. Perkin Trans. 2 1991, 87-99.

12. Wessels, B.W.; Rogus, R.D. Med. Phys. 1984, 11, 638-645.

13. Hnatowich, D.J.; Virzi, F.; Doherty, P.W. J. Nucl. Med. 1985, 26, 503-509.

14. Gansow, O.A. Nucl. Med. Biol. 1991, 18, 369-381.

15. Gansow, O.A. In New Trends in Radiopharmaceutical Synthesis, Quality Assurance and Regulatory Control, Ed.; Ali M. Emran, Plenum Press, 1991, pp 227-246.

16. Ruegg, C.L., Anderson-Berg, W.T., Brechbiel, M.W., Mirzadeh, S., Gansow, O.A., Strand, M. Cancer Res., 1990, 50, 4221-4226.

17. Takenouchi, K.; Watenabe, K.,; Kato, Y.; Koike, T.; Kimura, E.; J. Org. Chem. 1993, 58, $1955-198$.

18. Brechbiel, M.W.,; Gansow, O.A., Atcher, R.W.; Schlom, J.; Esteban, J.; Simpson, D.; Colcher, D. Inorg. Chem., 1986, 25, 2772-2781.

19. Robert, J.C.; Adams, Y.E.; Tomalia, D.; Mercer-Smith, J.A.; Lavallee, D.K. Bioconjugate Chem. 1990, 1, 305-308.

20. Barth, R.F.; Soloway, A.H.; Adams, D.M; Alam, F.; Progress in Neutron Capture Therapy for Cancer; Ed.; Allen, B.J., Ed,; Plenum Press: New York, 1992, pp. 265-268.

21. Barth, R.F.; Adams, D.M.; Soloway, A.H.; Alam, F.; Darby, M.V. Antibody, Immunoconj. Radiopharm. 1993, 6, 63.

22. Manabe, Y.; Longley, C.; Furmanski, P. Biochim. Biophys. Acta, 1986, 883, $460-467$.

23. Slinkin, M.A.; Klibanov, A.L.; Torchilin, V.P. Bioconjugate Chem. 1991, 2, 342-348.

24. Klibanov, A.L.; Slinkin, M.A.; Torchilin, V.P. Appl. Biochem. Biotech. 1989, 22, 45-58.

25. Shreve, P.; Aisen A.M. Magn. Res. Med. 1986, 3, 336-340.

26. Torchilin, V.P.; Klibanov, A.L.; Nossiff, N.D.; Slinkin, M.A.; Strauss, H.W.; Haber, E.; Smirnov, V.N.; Khaw, B.A. Hybridoma, 1987, 6, 229-240.

27. Tomalia, D.A.; Naylor, A.M.; Goddard, W.A. Angew. Chem. Int. Ed. Engl. 1990, 29, 138-175.

28. Brechbiel, M.W.; Gansow O.A. J. Chem. Soc. Perkin Trans. 1 1992, 1173-1178. 
29. McMurry T.J.; Brechbiel M.; Kumar, K.; Gansow, O.A. Bioconjugate Chem. 1992, 3, 108-117.

30. Carlsson, J.; Drevin, H.; Axen, R. B. Biochem. J. 1978, 173, 723-737.

31. (a) Ellman, G.L. Arch. Biochem. Biophys. 1959, 82, 70-77. (b) Riddles, P.W.; Blakeley, R.L.; Zernerä B. Anal. Biochem. 1979, 94, 75-81. Construct 4 is stable for at least 3 months when stored at $4^{\circ} \mathrm{C}$ and under vacuum in a desiccator.

32 Udenfriend, S.; Stein, S.; Bohlen, P.; Dairman, W. Science, 1972, 178, 871-872.

33. The procedure for the purification of 4 is as follows: The reaction mixture $(0.15-0.20 \mu \mathrm{M}$ in $250 \mu \mathrm{L})$ was loaded on a column of MP- 1 anion exchange resin $(2 \times 20 \mathrm{~mm})$ pre-equilibrated with $0.02 \mathrm{M} \mathrm{Tris} / \mathrm{HCl}$, $\mathrm{pH} 8.2$ and $0.1 \mathrm{M}$ in $\mathrm{NaCl}$. The column was eluted with $2 \mathrm{~mL}$ of the same buffer and then $1 \mathrm{~mL}$ water. 4 was eluted with $0.4 \mathrm{~mL}$ of $0.2 \mathrm{M} \mathrm{HCl}$ in $85 \%$ yield.

34. The procedure for the introduction of the maleimide and subsequent conjugation of mAb with 4 is as follows: mAb was first reacted with sulfo-SMCC in bicarbonate buffer, $\mathrm{pH} 8.5$ at room temperature for 20 min at an initial sulfo-SMCC to $\mathrm{mAb}$ molar ratio of $4: 1$. The unreacted regent was removed by Sephadex G50 exclusion chromatography with aqueous $0.02 \mathrm{M}$ Bis-Tris/ $\mathrm{HCl}, 0.1 \mathrm{M} \mathrm{NaCl}, \mathrm{pH} 7.0$ as eluant. Maleimide groups attached to mAbs were determinated by incubation with a known amount of 2 mercaptoethylamine and then by measuring remaining thiol groups using Ellman's method. ${ }^{31}$ Alternatively, sulfo-SMCC modified antibodies were reacted with a molar excess (10:1) of cysteine doped with ${ }^{35}$ S-cysteine and the number of maleimide groups was then determined by liquid scintillation counting after purification by ultracentrifugation. Typical conditions for the conjugation of derivatized $\mathrm{mAb}$ with 4 were $\mathrm{pH} 7.0$, room temperature, 30-60min. incubation time and 1.5-2.0 of dendrimer constructs to protein molar ratio. The reaction was quenched with $\mathrm{N}$-ethylmaleimide. This coupling reaction has been investigated in detail. The major results were as follows: (1) Solution pH between 6.59.0 had no significant effect in term of coupling efficiency; (2) The conjugation reaction was finished after ca. $1 \mathrm{~h}$ at $\mathrm{pH} 7.0$ and room temperature (85\% coupling efficiency for initial ratio of 4 to mAb was $0.75: 1.0$ ). However, $70 \%$ and $80 \%$ coupling efficiencies were observed after 5 and 30 min., respectively. (3) High molecular weight species decreased with increasing the molar ratio of 4 to $\mathrm{mAb}-\mathrm{SMCC}$.

35. Purification of antibody-dendrimer-ligand conjugates: The reaction mixture (5-15 mg mAb) was loaded onto MONO Q column and the free antibody eluted with buffer $\mathbf{A}(0.02 \mathrm{M} \mathrm{Bis-Tris} / \mathrm{HCl}, 0.1 \mathrm{M} \mathrm{NaCl}, \mathrm{pH}$ 7.0) at the flow rate of $1.0 \mathrm{~mL} / \mathrm{min}$. The TSK $3000 \mathrm{SW}$ column was then connected with the MONO $Q$ column by switching the $\mathrm{V} 7$ valve. The conjugated and unreacted dendrimer-ligand were eluted from

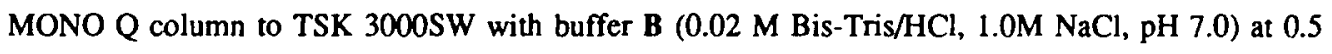
$\mathrm{mL} / \mathrm{min}$ for $20 \mathrm{~min}$. The TSK $3000 \mathrm{SW}$ column was then eluted with buffer $A$ at $2.0 \mathrm{~mL} / \mathrm{min}$ to separate antibody conjugated dendrimer-ligand from free dendrimer-ligand.

36. Only $6.0 \pm 0.4 \%$ of ${ }^{11}$ In-labeled $2 E 4$ was bound to negative control RAJI cells.

37 Wiener, E.C.; Brechbiel, M.W.; Brothers, H.; Magin, R.L.; Gansow, O.A.; Tomalia, D.A.; Lauterbur, P.C. Mag. Res. Med. (Accepted for Publication).

(Received in USA 22 October 1993; accepted 8 November 1993) 